\title{
Surgical and quality of life outcomes after pelvic organ prolapse surgery in older postmenopausal women
}

\author{
Mohamed M. Farghali ${ }^{1}$, Abeer Abdelzaher ${ }^{2}$, Ibrahim A. Abdelazim ${ }^{1,3}$ \\ ${ }^{1}$ Department of Obstetrics and Gynecology, Ain Shams University, Cairo, Egypt \\ ${ }^{2}$ Department of Geriatric Medicine, Ain Shams University, Cairo, Egypt \\ ${ }^{3}$ Department of Obstetrics and Gynecology, Ahmadi Hospital, Kuwait Oil Company (KOC), Kuwait
}

\begin{abstract}
Introduction: To evaluate the surgical outcome, and quality of life (QoL) 12-months after Le Fort colpocleisis (LFC), and sacrospinous fixation (SSF) in older postmenopausal women.

Material and methods: Eighty-six (86) post-menopausal women were included in this study (38 in the LFC group and 48 in the SSF group). Pelvic organ prolapse quantification (POP-Q) was used to evaluate the participants' pelvic organ prolapse (POP) pre-operatively and post-operatively (PO). The Arabic version of the WHOQoL-BREF Inventory was used to evaluate the participants' QoL preoperatively and post-operatively. The surgical outcome and QoL 12-months after LFC and SSF were analysed to evaluate the surgical outcome, as well as QoL 12 months after LFC and SSF.

Results: The pre-operative $\mathrm{Aa}, \mathrm{Ba}, \mathrm{D}, \mathrm{Ap}$, and $\mathrm{Bp}$ values of $\mathrm{POP}-\mathrm{Q}$ significantly improved 12 months $\mathrm{PO}$ in the LFC group ( $p 1=0.004,0.0006,0.02,0.004$, and 0.0001; respectively), and in the SSF group ( $p 1=0.003,0.0003$, $0.003,0.0005$, and 0.01 , respectively). Eighty $(93.02 \%)$ of the studied women had no prolapse at 12 -month PO follow-up. The 12-month PO psychological and social health domains were significantly higher in the SSF group compared to the LFC group ( $p 2=0.04$, and 0.02 , respectively). In addition, the 12 -month PO general health satisfaction and total QoL scores were significantly higher in the SSF group compared to the LFC group ( $p 2=0.03$ and 0.01 , respectively).

Conclusions: LFC can be considered a good surgical procedure with minimal or neglectable complications for POP in older postmenopausal women with multiple co-morbidities. The psychological and social health domains, general health satisfaction, and total QoL score were significantly higher in the SSF group compared to LFC group 12 months PO.
\end{abstract}

Key words: quality of life, pelvic organ prolapse, menopause.

\section{Introduction}

As life expectancy increases, so aging-related diseases increases [1]. The distorted body image associated with pelvic organ prolapse (POP) can harm women's quality of life (QoL) and their wellbeing [2].

The World Health Organization (WHO) defines QoL as "individuals' perceptions of their position in life in relation to the culture and values in which they live, and in relation to their goals, expectations, standards, and concerns" [3]. It is a broad concept including the person's physical and psychological status, level of independence, social relationships, and relationships with their environment [3].

POP can cause serious complaints because of hampered hygiene and limited mobility [2]. The most common symptoms of POP are a feeling of pressure or protrusion from the vagina, urinary incontinence (UI) or retention, voiding difficulties, and low backache. The symptoms associated with POP can cause significant disability affecting the QoL [4].

Various surgical procedures have been suggested for POP treatment, including colporrhaphy (with or without mesh placement), sacrospinous fixation (SSF), sacrocolpopexy, and colpocleisis. These surgical procedures differ in both success and complication rates. SSF is a technically challenging approach because the surgical site is deep and narrow. Although, several studies concluded that SSF is a safe and effective treatment in cases of uterine or vaginal vault prolapse $[5,6]$, it carries risk of complications including, haemorrhage, infection, and nerve damage.

Surgical treatment options of POP can be classified to either reconstructive or obliterative procedures. The reconstructive procedure, usually done after hysterectomy, can restore the vaginal depth and function, while the obliterative procedure is done as an effective alternative for correction of 
apical prolapse in old women who do not seek coital function [7].

An increasing number of old and healthy women are choosing the obliterative procedure due to its high success rate and quick recovery [8]. Le Fort colpocleisis (LFC) is the preferred obliterative surgical procedure for POP $[9,10]$. Although LFC is an effective procedure for $P O P$, its drawbacks include future evaluation of the cervix, vaginal discharge, and an uncomfortable feeling of fullness in the vagina [11].

Recent reports on LFC are mostly case series with poorly defined post-operative outcomes and follow-ups $[12,13]$. There is only scarce literature about QoL after correction of POP in older women. This study was designed to evaluate the surgical outcome and QoL 12 months after LFC and SSF in older postmenopausal women.

\section{Material and methods}

This prospective comparative study was conducted from January 2015 to May 2019, after approval by the ethical committee of the Obstetrics and Gynaecology department.

Eighty-six (86) post-menopausal women $\geq 65$ years old with $\geq$ stage II vault prolapse were included in this study after informed consent in accordance with the Declaration of Helsinki.

Exclusion criteria included smoking, obesity (body mass index - BMI > 35), history of strenuous activity in the form of frequent heavy lifting $>50 \mathrm{~kg}$ as per job requirement [14], previous abdominal/pelvic surgery other than hysterectomy, and previous history of endometriosis and/or pelvic inflammatory disease.

Women with chronic circulatory disorders, autoimmune and/or neoplastic disease other than endometrial carcinoma, urinary incontinence, cognitive impairment, and unreliable women for post-operative follow-up were also excluded from this study. Six (6) women were excluded at the beginning of this study, and the causes of exclusion are summarized in the study flow-chart (Fig. 1).

\begin{tabular}{|c|l|}
\hline $\begin{array}{c}\text { Eighty-six (86) } \\
\text { studied women }\end{array}$ & $\begin{array}{l}\text { Six (6) women excluded } \\
\text { from this study }\end{array}$ \\
\hline \begin{tabular}{c|l|} 
Thirty-eight (38) \\
women in LFC group
\end{tabular} & $\begin{array}{l}\text { Causes of exclusion } \\
\text { Obesity and history } \\
\text { of endometriosis ( } n=2)\end{array}$ \\
\hline $\begin{array}{l}\text { Forty-eight (48) } \\
\text { women in SSF group }\end{array}$ & $\begin{array}{l}\text { Strenuous activity + smoking }(n=1) \\
\text { Chronic circulatory disorder + } \\
\text { autoimmune disease (SLE) }(n=1) \\
\text { Neoplastic diseases (thyroid } \\
\text { malignancy) (n=1) }\end{array}$ \\
\hline
\end{tabular}

Fig. 1. The study flow chart
Participants were subjected to thorough history to record their age, BMI, parity, medical co-morbidities (diabetes mellitus, thyroid disorders, cardiovascular, liver, renal diseases), neurological diseases (stroke, cerebrovascular attacks), neuropsychiatric disorders, and non-gynaecological malignancies.

Participants underwent standard physical examination and evaluation of their prolapse using the POP quantification (POP-Q) suggested by the International Continence Society (ICS), American Urogynecologic Society (AUGS), and Society of Gynecologic Surgeons [8]. The POP-Q was used for the objective measurement of POP according to 6 distinct locations ( $\mathrm{Aa}, \mathrm{Ba}, \mathrm{C}, \mathrm{D}, \mathrm{Ap}$, $\mathrm{Bp})$ and 3 anatomical markers (gh, pb, tvl) [8].

Participants were examined in a supine position, and the maximum prolapse was evaluated by asking participants to cough or to perform a Valsalva manoeuvre. POP was evaluated using POP-Q, and the stage of $P O P$ in relation to hymen was recorded.

Stage 0: No prolapse is observed (all Aa, Ba, C, D, Ap, and $\mathrm{Bp}$ points are $\leq-3 \mathrm{~cm}$ ).

Stage 1: The prolapse is $>1 \mathrm{~cm}$ above the hymen (all $\mathrm{Aa}, \mathrm{Ba}, \mathrm{C}, \mathrm{D}, \mathrm{Ap}$, and $\mathrm{Bp}$ points are $<-1 \mathrm{~cm}$ ).

Stage 2: The prolapse is $1 \mathrm{~cm}$ above or below the hymen (points $\mathrm{Aa}, \mathrm{Ba}, \mathrm{C}, \mathrm{D}, \mathrm{Ap}$, and Bp points are -1 or $+1 \mathrm{~cm})$.

Stage 3: The prolapse $>1 \mathrm{~cm}$ below the hymen but $<2 \mathrm{~cm}$ of tvl (points $\mathrm{Aa}, \mathrm{Ba}, \mathrm{C}, \mathrm{D}, \mathrm{Ap}$, and Bp are $\geq+2 \mathrm{~cm}$ and $<\mathrm{tvl}-3 \mathrm{~cm}$ ).

Stage 4: Vaginal eversion with $2 \mathrm{~cm}$ of $\mathrm{tvl}(\mathrm{Aa}, \mathrm{Ba}, \mathrm{C}$, $D, A p$, and Bp points are $\geq \mathrm{tvl}-2 \mathrm{~cm}$ ).

Eligible women were assigned to either the LFC group or the SSF group, after giving informed written consent (based on their choice after counselling). Surgeries were performed by an experienced gynaecologist ( $\geq 12$ years' experience after MD degree and $\geq 80$ LFC and SSF procedures).

LFC procedure: Rectangular shapes on the anterior and posterior vaginal walls were demarcated with sterile marker; then, the anterior and posterior vaginal epithelial tissue were stripped with sharp dissection and the edges of each distal quadrangle were sutured together. The denuded areas were sutured together frontto-back in progressive rows using (Vicryl 2-0, Ethicon, NJ, USA) interrupted sutures. The prolapsed parts were inserted into the vaginal cavity, leaving lateral tunnel on each side followed by levator ani plication and posterior perineorrhaphy.

SSF procedure: SSF procedures were performed unilaterally to the right sacrospinous ligament. The rectovaginal space was dissected to separate it from the rectum following posterior vaginal wall incision. The pararectal space was entered to access the sacrospinous ligament (SSL). The SSL was made visible via blunt dissection following palpation of the ischial spine. One permanent suture (Prolene 1.0, Ethicon, NJ, USA) and 
one delayed absorbable suture (Vicryl 1.0, Ethicon, NJ, USA) were placed through the right SSL (at least $2 \mathrm{~cm}$ from the ischial spine) to the vaginal apex. The sacrospinous sutures were tied to elevate the vaginal apex towards the SSL after closure of the upper $2 / 3$ of the posterior vaginal wall incision with absorbable (Vicryl 2) sutures. Then the lower $1 / 3$ of the posterior vaginal wall incision was sutured, followed by anterior and/or posterior colporrhaphies.

The Arabic version of the WHOQoL-BREF Inventory [15] was used to evaluate the participants' QoL preoperatively and post-operatively. The total WHOQoL score based on 26-items (minimum score 26, while maximum score 130 - higher scores indicating better QoL). The WHOQoL includes 4 domains (physical, psychological, social, and environment health domains) in addition to general quality of life and general health satisfaction $[15,16]$. Because of reading and visual difficulties among the elderly studied women, their QoL was assessed during direct interview by 2 investigators who were blinded to the pre-operative stage of POP and the surgical procedures done (to avoid potential bias affecting the study results).

Post-operative (PO) follow-up of the participants was done at 6 weeks and 3, 6, and 12 months PO. The surgical outcome and QoL 12 months after LFC and SSF were analysed to evaluate the surgical outcome (primary outcome), and QoL (secondary outcome) 12 months after LFC and SSF.

\section{Statistical analysis}

Statistical analysis was done using STATA version 14 (software for statistics and data science, STATA Corp., Texas, USA). Numerical variables were presented as mean and standard deviation ( \pm SD), while categorical variables were presented as number $(n)$ and percentage (\%). The $\chi^{2}$ test was used to compare qualitative variables, and Student's t-test was used to compare numerical variables. Primary outcome measures, the surgical outcome 12 months after LFC and SSF, while the secondary outcome measures, the QoL 12-months after LFC and SSF. $P$-value $<0.05$ was considered significant.

\section{Results}

Eighty-six (86) post-menopausal women were included in this study (38 in the LFC group and 48 in the SSF group) after approval of the study and informed consent in accordance with the Declaration of Helsinki.

There was no significant difference between the 2 studied groups regarding mean age, parity, BMI, indications of hysterectomy [17-19], medical comorbidities, and per-operative prolapse stage (Table 1).

The surgical procedures, either LFS or SSF, were done under general anaesthesia in 6.98\% (6/86), and under epidural anaesthesia in $93.02 \%(80 / 86)$ of the studied cases. There was no significant difference between the 2 studied groups regarding the operative time $(59.5 \pm$ $11.2 \mathrm{~min}$ in the LFC group vs. $65 \pm 16.2 \mathrm{~min}$ in the SSF group ( $p=0.9$ [95\% Cl: $-11.4,-5.5,0.4]$ ), intra-operative estimated blood loss (EBL) $(442.5 \pm 45.8 \mathrm{~mL}$ in the LFC group vs. $539 \pm 68.7 \mathrm{~mL}$ in the SSF group ( $p=0.9[95 \%$ Cl: 121.2, -96.5, -71.8]), and post-operative hospital stay $(2.8 \pm 1.7$ days in the LFC group vs. $3.2 \pm 2.9$ days in the SSF group ( $p=0.9$ [95\% Cl: $-1.4,-0.4,0.61])$. One woman (1/48 [2.08\%]) in the SSF group had intra-operative bleeding due to injury of the inferior gluteal vein, controlled by compression. Two women (2/48 [4.16\%]) in the SSF group had PO urinary retention managed by Foley`s catheter insertion and bladder training. No intra-operative or PO complications were recorded in the LFC group. There was no significant difference between the 2 studied groups regarding the intra-operative $(p=0.2)$ or PO complications $(p=0.1)$ (Table 1$)$.

There was no significant difference between the 2 studied group regarding the pre-operative $\mathrm{Aa}, \mathrm{Ba}$, C, D, Ap, Bp, gh, pb, and tvl values of the POP-Q. The pre-operative $\mathrm{Aa}, \mathrm{Ba}, \mathrm{D}, \mathrm{Ap}$, and $\mathrm{Bp}$ values of the $\mathrm{POP}-\mathrm{Q}$ significantly improved 12 months PO in the LFC group ( $p 1=0.004,0.0006,0.02,0.004$, and 0.0001, respectively) and in the SSF group ( $p 1=0.003,0.0003,0.003$, 0.0005 , and 0.01 , respectively). In addition, there was no significant difference between the 2 studied groups regarding the 12-month $\mathrm{PO} \mathrm{Aa}, \mathrm{Ba}, \mathrm{C}, \mathrm{D}, \mathrm{Ap}, \mathrm{Bp}$, gh, pb, and tvl values of the POP-Q (Table 2).

Eighty (93.02\%) of the studied women had no prolapse at 12-month PO follow-up, while 6 (6.98\%) of them had asymptomatic stage I prolapse (3 after SSF and 3 after LFC), and none of them required additional surgery.

There was no significant difference between the two studied groups regarding the pre-operative physical, psychological, social, and environmental health domains, general QoL, general health satisfaction, and total QoL score (Table 3).

The pre-operative physical, psychological, and social health domains of the WHOQOL score significantly improved 12 months PO in LFC group ( $p 1=0.04,0.02$, and 0.02 , respectively) and in the SSF group ( $p 1=0.02$, 0.0002 , and 0.0001 , respectively). In addition, the preoperative general health satisfaction and total QoL score significantly improved 12 months PO in the LFC group ( $p 1=0.04$ and 0.01 , respectively) and in the SSF group ( $p 1=0.003$ and 0.0001 , respectively) (Table 3 ).

The 12-month PO psychological and social health domains were significantly higher in the SSF group compared to the LFC group ( $p 2=0.04[95 \% \mathrm{Cl}:-8.8$, $-4.1,0.6$ ], and 0.02 [95\% Cl: $-5.6,-1.2,3.2$ ], respectively). In addition, the 12-month PO general health satisfaction and total QoL scores were significantly higher in the SSF group compared to the LFC group ( $p 2=0.03$ 
Table 1. Characteristics of the studied groups, operative time, estimated blood loss, post-operative complications, and hospital stay

\begin{tabular}{|c|c|c|c|}
\hline Variables & $\begin{array}{c}\text { Le Fort colpocleisis } \\
\text { (LFC group }=38 \text { women) }\end{array}$ & $\begin{array}{l}\text { Sacrospinous fixation } \\
\text { (SSF group = } 48 \text { women) }\end{array}$ & $p$-value $(95 \% \mathrm{Cl})$ \\
\hline Age (years) & $72.6 \pm 5.1$ & $69.9 \pm 4.6$ & $0.2(0.6,2.7,4.8)$ \\
\hline Parity & $4.3 \pm 2.6$ & $4.5 \pm 2.5$ & $0.3(-1.3,-0.2,0.9)$ \\
\hline BMI $\left(\mathrm{kg} / \mathrm{m}^{2}\right)$ & $28.2 \pm 5.1$ & $29.6 \pm 4.2$ & $0.1(-3.5,-1.4,0.7)$ \\
\hline \multicolumn{4}{|l|}{ Indications of hysterectomy } \\
\hline Fibroid uterus & 19 & 22 & 0.8 \\
\hline Adenomyosis & 5 & 6 & 1.0 \\
\hline AUB & 2 & 3 & 0.8 \\
\hline Endometrial carcinoma & 3 & 4 & 1.0 \\
\hline Uterine prolapse > stage II & 5 & 9 & 0.5 \\
\hline Ovarian Pathology & 4 & 4 & 0.7 \\
\hline Comorbidity & $34(89.47 \%)$ & $42(87.5 \%)$ & 1.0 \\
\hline Diabetes mellitus & 24 & 30 & 1.0 \\
\hline Hypertension & 10 & 18 & 0.4 \\
\hline Hypercholesterolaemia & 21 & 15 & 0.1 \\
\hline Hypothyroidism & 7 & 12 & 0.5 \\
\hline COPD & 1 & 2 & 0.7 \\
\hline Cardiovascular accidents & 1 & 2 & 0.7 \\
\hline \multicolumn{4}{|l|}{ Pre-operative prolapse stage } \\
\hline Stage II & $9(23.7 \%)$ & $10(20.8 \%)$ & 0.8 \\
\hline Stage III & $16(42.1 \%)$ & $20(41.7 \%)$ & 1.0 \\
\hline Stage IV & $13(34.2 \%)$ & $18(37.5 \%)$ & 0.8 \\
\hline Operative time (min) & $59.5 \pm 11.2$ & $65 \pm 16.2$ & $0.9(-11.4,-5.5,0.4)$ \\
\hline Intra-operative EBL (ml) & $442.5 \pm 45.8$ & $539 \pm 68.7$ & $0.9(-121.2,-96.5,-71.8)$ \\
\hline Intra-operative complications & $0(0 \%)$ & $1(2.08 \%)$ & 0.2 \\
\hline Post-operative complications & $0(0 \%)$ & $2(4.16 \%)$ & 0.1 \\
\hline Post-operative hospital stay (days) & $2.8 \pm 1.7$ & $3.2 \pm 2.9$ & $0.9(-1.4,-0.4,0.61)$ \\
\hline
\end{tabular}

AUB - abnormal uterine bleeding, BMI - body mass index, $\mathrm{Cl}$ - confidence interval, $\chi^{2}$-test - used for statistical analysis when data presented as number and percentage (\%), COPD - chronic obstructive pulmonary disease. Data presented as mean \pm standard deviation (SD) and number and percentage (\%), $\mathrm{EBL}$ - estimated blood loss. Student's $t$-test used for statistical analysis when the data presented as mean \pm SD

[95\% Cl: $-1.8,-0.2,1.4]$, and 0.01 [95\% Cl: $-9.7,-3.7,2.3]$, respectively) (Table 3).

\section{Discussion}

POP is a major concern among older women. A small number of women who suffer from POP will be operated; most of them just receive conservative treatment and never present to physician [11, 12].

POP symptoms can cause significant disability, affecting the QoL [4]. LFC is the least invasive and most durable surgical procedure available for the treatment of POP in older women [20].

Therefore, 86 post-menopausal women were included in this study (38 in the LFC group and 48 in the SSF group) to evaluate the surgical outcome and QoL 12 months after LFC and SSF in older postmenopausal women.
There was no significant difference between the 2 studied groups regarding mean age, parity, BMI, indications of hysterectomy, medical comorbidities, and per-operative prolapse stage. In addition, there was no significant difference between the 2 studied groups regarding the operative time $(p=0.9)$ and intra-operative EBL $(p=0.9)$. Medical co-morbidities were recorded in $34 / 38(89.47 \%)$ women of the LFC group and in $42 / 48$ $(87.5 \%)$ women of the SSF group.

$\mathrm{Ng}$ et al. reported at least one medical comorbidity in 20/22 (90.9\%), and > 2 comorbidities in 13/22 (59.1\%) women $>70$ years old with POP [21]. Ghezzi et al. found that $95.7 \%$ had $>1$ comorbidity, and only $4.3 \%$ had 1 medical comorbidity during treatment of pelvic floor dysfunction in advanced-age women [22].

In general, medical disorders and comorbidities increase with age. Age alone should not be the main reason for rejecting any surgical procedure in an older 
Table 2. Preoperative and 12-month post-operative pelvic organ prolapse quantification in the two studied groups

\begin{tabular}{|c|c|c|c|}
\hline & $\begin{array}{l}\text { Le Fort colpocleisis } \\
\text { (LFC group = } 38 \text { women) }\end{array}$ & $\begin{array}{l}\text { Sacrospinous fixation } \\
\text { (SSF group }=48 \text { women) }\end{array}$ & p2-value $(95 \% \mathrm{CI})$ \\
\hline \multicolumn{4}{|l|}{$\mathrm{Aa}$} \\
\hline Pre-operative & $1.8 \pm 1.4$ & $1.8 \pm 1.8$ & $0.9(-0.7,0,0.7)$ \\
\hline Post-operative & $-2.7 \pm 0.9$ & $-1.9 \pm 1.2$ & $0.9(-1.2,-0.8,0.3)$ \\
\hline p1-value $(95 \% \mathrm{Cl})$ & $0.004^{*}(3.9,4.5,5)$ & $0.003^{*}(3.1,3.7,4.3)$ & \\
\hline \multicolumn{4}{|l|}{$\mathrm{Ba}$} \\
\hline Pre-operative & $3.2 \pm 1.9$ & $2.5 \pm 1.5$ & $0.06(-0.05,0.7,1.5)$ \\
\hline Post-operative & $-2.5 \pm 1.1$ & $-1.8 \pm 0.9$ & $0.09(-1.1,-0.7,-0.3)$ \\
\hline p1-value $(95 \% \mathrm{Cl})$ & $0.0006^{*}(4.9,5.7,6.4)$ & $0.0003^{*}(3.8,4.3,4.8)$ & \\
\hline \multicolumn{4}{|l|}{$\mathrm{C}$} \\
\hline Pre-operative & $-1.7 \pm 3.7$ & $-1.8 \pm 4.3$ & $0.8(-1.6,0.1,1.8)$ \\
\hline Post-operative & $-6.6 \pm 4.4$ & $-3.6 \pm 4.5$ & $0.5(-4.9,-3,-1.07)$ \\
\hline p1-value (95\% Cl) & $0.8(3,4.9,6.8)$ & $0.6(0.02,1.8,3.6)$ & \\
\hline \multicolumn{4}{|l|}{ D } \\
\hline Pre-operative & $-3.4 \pm 4.6$ & $-2.7 \pm 4.8$ & $0.6(-2.7,-0.7,1.3)$ \\
\hline Post-operative & $-5.7 \pm 3.3$ & $-6.1 \pm 3.2$ & $0.4(-1.0,0.4,1.8)$ \\
\hline p1-value $(95 \% \mathrm{Cl})$ & $0.02 *(0.5,2.3,4.1)$ & $0.003^{*}(1.7,3.4,5.1)$ & \\
\hline \multicolumn{4}{|l|}{ Ap } \\
\hline Pre-operative & $-1.8 \pm 3.4$ & $-1.9 \pm 1.3$ & $0.0(-1.1,0.1,1.3)$ \\
\hline Post-operative & $-8.9 \pm 2.2$ & $-9.04 \pm 0.8$ & $0.0(-0.6,0.1,0.9)$ \\
\hline p1-value $(95 \% \mathrm{Cl})$ & $0.004^{*}(5.8,7.1,8.4)$ & $0.0005^{*}(6.7,7.1,7.6)$ & \\
\hline \multicolumn{4}{|l|}{$\mathrm{Bp}$} \\
\hline Pre-operative & $1.4 \pm 2.6$ & $1.3 \pm 3.03$ & $0.8(-1.1,0.1,1.3)$ \\
\hline Post-operative & $-5.2 \pm 1.4$ & $-5.8 \pm 2.2$ & $0.9(-0.18,0.6,1.4)$ \\
\hline p1-value $(95 \% \mathrm{Cl})$ & $0.0001^{*}(5.6,6.6,7.6)$ & $0.01^{*}(6,7.1,8.2)$ & \\
\hline \multicolumn{4}{|l|}{ gh } \\
\hline Pre-operative & $4.6 \pm 0.9$ & $4.9 \pm 1.1$ & $0.9(-0.7,-0.3,0.13)$ \\
\hline Post-operative & $2.9 \pm 0.7$ & $2.7 \pm 1.6$ & $1.0(-0.3,0.2,0.7)$ \\
\hline p1-value $(95 \% \mathrm{Cl})$ & $0.06(1.3,1.7,2.1)$ & $0.9(1.6,2.2,2.8)$ & \\
\hline \multicolumn{4}{|l|}{$\mathrm{pb}$} \\
\hline Pre-operative & $2.1 \pm 0.6$ & $2.3 \pm 0.7$ & $0.8(-0.48,-0.2,0.07)$ \\
\hline Post-operative & $4.2 \pm 0.7$ & $4.1 \pm 0.9$ & $0.9(-0.2,0.1,0.4)$ \\
\hline p1-value $(95 \% \mathrm{Cl})$ & $0.8(-2.4,-2.1,-1.8)$ & $0.9(-2.1,-1.8,-1.5)$ & \\
\hline \multicolumn{4}{|l|}{ tvl } \\
\hline Pre-operative & $9.6 \pm 1.02$ & $9.5 \pm 1.7$ & $0.9(-0.5,0.1,0.7)$ \\
\hline Post-operative & $9.8 \pm 0.9$ & $9.3 \pm 2.3$ & $1.0(-0.22,0.5,1.2)$ \\
\hline p1-value $(95 \% \mathrm{Cl})$ & $0.2(-0.6,-0.2,0.2)$ & $0.9(-0.6,0.2,1)$ & \\
\hline
\end{tabular}

* - significant difference, $\mathrm{Cl}$ - confidence interval. Data presented as mean \pm standard deviation (SD), p1 value used when the pre-operative and postoperative variables compared within the same group, $p 2$ value used when the pre-operative or postoperative variables compared between the two studied groups, Student's t-test - used for statistical analysis, POP-Q - pelvic organ prolapse quantification, Aa - refers to midline of anterior vaginal wall, $3 \mathrm{~cm}$ up from the hymen when there is no prolapse, $\mathrm{Ba}$ - refers to anterior vaginal wall mid-way between $\mathrm{Aa}$ and anterior fornix when there is no prolapse, $\mathrm{C}$ - cervix (lowest edge or vaginal cuff following hysterectomy), D - Douglas pouch, Ap - refers to the midline of posterior vaginal wall $3 \mathrm{~cm}$ proximal to hymen, $\mathrm{Bp}$ - refers to posterior vaginal wall mid-way between Ap and posterior fornix when there is no prolapse, gh - genital hiatus, refers to the length from the urethral opening to the posterior vaginal opening, pb - perineal body, refers to length from the posterior aspect of hymen to the mid-anal opening, $\mathrm{tvl}$ - total vaginal length, measured from hymen to the most distal point to assess of the depth of prolapse before, and after surgical correction

woman. Furthermore, it is important to take the QoL into consideration. The decision to perform surgery should be extensively discussed with the patient and her relatives [23].
In the SSF studied group, 1 woman (1/48 [2.08\%]) had intra-operative bleeding due to injury of the inferior gluteal vein (controlled by compression), and two women (2/48 [4.16\%]) had PO urinary retention (man- 
Table 3. Preoperative and 12-month post-operative quality of life in the two studied groups

\begin{tabular}{|c|c|c|c|}
\hline & $\begin{array}{c}\text { Le Fort colpocleisis } \\
\text { (LFC group = } 38 \text { women) }\end{array}$ & $\begin{array}{l}\text { Sacrospinous fixation } \\
\text { (SSF group = } 48 \text { women) }\end{array}$ & p2-value $(95 \% \mathrm{Cl})$ \\
\hline \multicolumn{4}{|c|}{ Physical health domain } \\
\hline Pre-operative & $43.5 \pm 13.2$ & $44.4 \pm 12.4$ & $0.3(-6.5,-0.9,4.7)$ \\
\hline Post-operative & $49.3 \pm 9.9$ & $48.4 \pm 9.2$ & $0.3(-3.2,0.9,5.0)$ \\
\hline p1-value $(95 \% \mathrm{Cl})$ & $0.04^{*}(-11.2,-5.8,-0.4)$ & $0.02 *(-8.4,-4,0.44)$ & \\
\hline \multicolumn{4}{|c|}{ Psychological health domain } \\
\hline Pre-operative & $52.9 \pm 16.6$ & $53.4 \pm 15.6$ & $0.3(-7.5,-0.5,6.5)$ \\
\hline Post-operative & $56.3 \pm 11.9$ & $60.4 \pm 9.2$ & $0.04^{*}(-8.8,-4.1,0.6)$ \\
\hline p1-value $(95 \% \mathrm{Cl})$ & $0.02^{*}(-9.9,-3.4,3.2)$ & $0.0002^{*}(-12.2,-7,-1.8)$ & \\
\hline \multicolumn{4}{|c|}{ Social health domain } \\
\hline Pre-operative & $46.7 \pm 15.5$ & $47.8 \pm 14.2$ & $0.2(-7.6,-1.1,5.4)$ \\
\hline Post-operative & $50.6 \pm 11.2$ & $51.8 \pm 8.3$ & $0.02^{*}(-5.6,-1.2,3.2)$ \\
\hline p1-value $(95 \% \mathrm{Cl})$ & $0.02^{*}(-10,-3.9,2.3)$ & $0.0001^{*}(-8.7,4,0.7)$ & \\
\hline \multicolumn{4}{|c|}{ Environment health domain } \\
\hline Pre-operative & $45.6 \pm 10.9$ & $44.8 \pm 12.6$ & $0.8(-4.2,0.8,5.8)$ \\
\hline Post-operative & $47.9 \pm 11.5$ & $46.5 \pm 12.4$ & $0.7(-3.7,1.4,6.5)$ \\
\hline p1-value $(95 \% \mathrm{Cl})$ & $0.6(-7.4,-2.3,2.8)$ & $0.4(-6.8,-1.7,3.4)$ & \\
\hline \multicolumn{4}{|c|}{ General quality of life } \\
\hline Pre-operative & $2.8 \pm 1.2$ & $2.8 \pm 1.3$ & $0.7(-0.5,0,0.5)$ \\
\hline Post-operative & $2.9 \pm 1.3$ & $3.1 \pm 1.4$ & $0.7(-0.8,-0.2,0.4)$ \\
\hline p1-value $(95 \% \mathrm{Cl})$ & $0.6(-0.7,-0.1,0.5)$ & $0.7(-0.8,-0.3,0.2)$ & \\
\hline \multicolumn{4}{|c|}{ General health satisfaction } \\
\hline Pre-operative & $2.7 \pm 5.5$ & $2.8 \pm 4.6$ & $0.1(-2.3,-0.1,2.1)$ \\
\hline Post-operative & $2.9 \pm 4.1$ & $3.1 \pm 3.1$ & $0.03^{*}(-1.8,-0.2,1.4)$ \\
\hline p1-value $(95 \% \mathrm{Cl})$ & $0.04^{*}(-2.4,-0.2,2)$ & $0.003^{*}(-1.9,-0.3,1.3)$ & \\
\hline \multicolumn{4}{|c|}{ Total quality of life score } \\
\hline Pre-operative & $80.5 \pm 22.6$ & $78.6 \pm 19.7$ & $0.1(-7.3,1.9,11.1)$ \\
\hline Post-operative & $92.1 \pm 15.6$ & $95.8 \pm 11.3$ & $0.01^{*}(-9.7,-3.7,2.3)$ \\
\hline p1-value $(95 \% \mathrm{Cl})$ & $0.01^{*}(-20.5,-11.6,-2.7)$ & $0.0001^{*}(-23.8,-17.2,-10.6)$ & \\
\hline
\end{tabular}

aged by Foley's catheter insertion and bladder training). No intra-operative or PO complications were recorded in the studied LFC group.

Sung et al. reported that women with extreme old age who underwent obliterative procedures had a lower risk of complication than those who underwent reconstructive procedures for POP (17 vs. $24.7 \%, p<0.01)$ [24]. Krissi et al. reported no intra-operative complications and 2 lower tract infections among women $>80$ years old who underwent LFC, with a subjective cure rate of $86.7 \%(20 / 23)$ [25].

Leijonhufvud et al. concluded that LFC is the least invasive and most durable surgical procedure available for treatment of POP in older women [20].

The pre-operative $\mathrm{Aa}, \mathrm{Ba}, \mathrm{D}, \mathrm{Ap}$, and $\mathrm{Bp}$ values of POP-Q significantly improved 12 months PO in the 2 studied groups. Eighty (93.02\%) of the studied wom- en had no prolapse at 12-month PO follow-up, while $6(6.98 \%)$ of them had asymptomatic stage I prolapse (none of them required surgery).

The largest colpocleisis study, by Zebede et al., reported an anatomical success rate of $98.1 \%$ after colpocleisis [26].

De-novo urinary incontinence may develop after POP surgery, which is referred to as occult stress urinary incontinence $[27,28]$. The bladder nerve damage during LFC are usually minimal, and most urinary symptoms after LFC are transient and self-resolving [28]. In addition, anti-incontinence surgery at the time of POP surgery is under debate [29].

Von Pechmann et al. reported 2 cases of rectal prolapse $(2.2 \%)$ in 92 women who underwent total colpocleisis [30]. They suggested that the plication of the levator ani during colpocleisis and correction of the an- 
terior pelvic floor weakness may result in posterior pelvic floor weakness and subsequent anorectal prolapse with increased intrabdominal pressure [30].

In this study, the pre-operative physical, psychological, and social health domains, general health satisfaction, and total QoL score were significantly improved PO in the 2 studied groups. In addition, the psychological and social health domains, general health satisfaction, and total QoL scores were significantly higher in the SSF group compared to the LFC group 12 months PO (p2 $=0.04,0.02 ; 0.03$, and 0.01, respectively).

Zebede et al. reported a $92.9 \%$ subjective satisfaction rate after colpocleisis [26]. Ng et al. reported a $93.8 \%$ satisfaction rate in women $>70$ years old with POP treated with obliterative LFC [21]. Song et al. reported a $94.3 \%$ satisfaction rate 5 years after LFC, and only 2 women were "neither satisfied nor dissatisfied" [31].

This study concluded that LFC can be considered a good surgical procedure with minimal or neglectable complications for POP in older women with multiple co-morbidities who do not seek coital function. Although the QoL significantly improved after both LFC and SSF, the psychological and social health domains, general health satisfaction, and total QoL scores were significantly higher in the SSF group compared to the LFC group 12 months PO.

Women refusing to give consent and/or participate, women with difficult communication, and being a single-centre study were the limitations of this study.

There is only scarce literature about QoL after surgical correction of POP in older women. This is the first study designed to evaluate the surgical outcome and QoL 12 months PO after LFC and SSF in older postmenopausal women using the Arabic version of the WHOQoL-BREF Inventory. Further future comparative studies using the WHOQoL-BREF Inventory are needed to confirm our findings.

\section{Conclusions}

Age alone should not be the main reason for rejecting any surgical procedure in an older woman, and it is important to take the QoL into consideration. LFC can be considered a good surgical procedure with minimal or neglectable complications for POP in older postmenopausal women with multiple co-morbidities who do not seek coital function. Although the QoL significantly improved in both LFC and SSF groups, the psychological and social health domains, general health satisfaction, and total QoL score were significantly higher in the SSF group compared to the LFC group 12 months PO.

\section{Acknowledgment}

The authors are grateful to the studied women who gave consent and participated in this study.
This study approval by the ethical committee of the Obstetrics and Gynaecology Department, and informed consent was obtained from the studied women in accordance with the Declaration of Helsinki.

\section{Disclosure}

The authors report no conflicts of interest.

\section{References}

1. Dieter AA, Wilkins MF, Wu JM. Epidemiological trends and future care needs for pelvic floor disorders. Curr Opin Obstet Gynecol 2015; 27 : 380-384.

2. Tarver T. Older Americans 2012: key indicators of wellbeing. J Consum Health Internet 2013; 17: 114-115.

3. Kim S. World Health Organization Quality of Life (WHOQoL) assessment. In: Michalos AC (eds). Encyclopedia of Quality of Life and WellBeing Research. Springer 2014, Dordrecht.

4. Harmanli O, Celik H, Jones KA, et al. Minimally invasive diagnosis, and treatment of endometrial cancer after Le Fort colpocleisis. Female Pelvic Med Reconstr Surg 2013; 19: 242-244.

5. Morgan DM, Rogers MA, Huebner M, et al. Heterogeneity in anatomic outcome of sacrospinous ligament fixation for prolapse: a systematic review. Obstet Gynecol 2007; 109: 1424-1433.

6. Dietz V, Huisman M, de Jong JM, et al. Functional outcome after sacrospinous hysteropexy for uterine descensus. Int Urogynecol J Pelvic Floor Dysfunct 2008; 19: 747-752

7. Park JY, Han SJ, Kim JH, et al. Le Fort partial colpocleisis as an effective treatment option for advanced apical prolapse in elderly women. Taiwan J Obstet Gynecol 2019; 58: 206-211.

8. Abbasy S, Kenton K. Obliterative procedures for pelvic organ prolapse. Clin Obstet Gynecol 2010; 53: 86-98.

9. Pizarro-Berdichevsky J, Galleguillos G, Cuevas R, et al. Labhardt's colpoperineocleisis: subjective results of an alternative treatment for genital prolapse in patients who are not sexually active--2-year follow-up. Int Urogynecol J 2014; 25: 417-424.

10. Thubert T, Daché A, Leguilchet T, et al. Colpocléisis selon la technique de Le Fort : une série rétrospective [Obliterative vaginal surgery for genital prolapse: a retrospective cases series]. Prog Urol 2012; 22: 1071-1076.

11. Lu YX, Hu ML, Wang WY, et al. [Colpocleisis in elderly patients with severe pelvic organ prolapse]. Zhonghua Fu Chan Ke Za Zhi 2010; 45: 331-337.

12. Crisp CC, Book NM, Smith AL, et al. Body image, regret, and satisfaction following colpocleisis. Am J Obstet Gynecol 2013; 209: 473.e1-7.

13. Bump RC, Mattiasson A, Bø K, et al. The standardization of terminology of female pelvic organ prolapse and pelvic floor dysfunction. Am J Obstet Gynecol 1996; 175: 10-17.

14. Forner LB, Beckman EM, Smith MD. Symptoms of pelvic organ prolapse in women who lift heavy weights for exercise: a cross-sectional survey. Int Urogynecol J 2020; 31: 1551-1558.

15. Aigner M, Förster-Streffleur S, Prause, et al. What does the WHOQoLBref measure? Soc Psychiat Epidemiol 2006; 41: 81-86.

16. Skevington SM, Carse MS, Williams AC. Validation of the WHOQoL-100: pain management improves quality of life for chronic pain patients. Clin J Pain 2001; 17: 264-275.

17. Abdelazim IA, AbuFaza M, Hamed MES, et al. Severe adenomyosis with unexpectedly high CA-125: report of a rare case. Prz Menopauzalny 2020; 19: 144-1146.

18. Abdelazim IA, AbuFaza M, Bekmukhambetov Y, et al. Postmenopausal adnexal torsion: rare case report. Prz Menopauzalny 2020; 19: 49-51.

19. Elbiaa AA, Abdelazim IA, Farghali MM, et al. Unexpected premalignant gynecological lesions in women undergoing vaginal hysterectomy for utero-vaginal prolapse. Prz Menopauzalny 2015; 14: 188-191.

20. Leijonhufvud A, Lundholm C, Cnattingius S, et al. Risks of stress urinary incontinence and pelvic organ prolapse surgery in relation to mode of childbirth. Am J Obstet Gynecol 2011; 204: 70. e1-7.

21. Ng SC, Chen GD. Obliterative Le Fort colpocleisis for pelvic organ prolapse in elderly women aged 70 years and over. Taiwan J Obstet Gynecol 2016; 55: 68-71. 
22. Ghezzi F, Uccella S, Cromi A, et al. Surgical treatment for pelvic floor disorders in women 75 years or older: a singlecenter experience. Menopause 2011; 18: 314e8.

23. Thakar R, Stanton S. Management of genital prolapse. BMJ 2002; 324: 1258-1262.

24. Sung VW, Weitzen S, Sokol ER, et al. Effect of patient age on increasing morbidity and mortality following urogynecologic surgery. Am J Obstet Gynecol 2006; 194: 1411-1417.

25. Krissi H, Aviram A, Ram E, et al. Colpocleisis surgery in women over 80 years old with severe triple compartment pelvic organ prolapse. Eur J Obstet Gynecol Reprod Biol 2015; 195: 206-209.

26. Zebede S, Smith AL, Plowright LN, et al. Obliterative Le Fort colpocleisis in a large group of elderly women. Obstet Gynecol 2013; 121: 279-284.

27. Romanzi LJ. Management of the urethral outlet in patients with severe prolapse. Curr Opin Urol 2002; 12: 339-344.

28. Alas AN, Chinthakanan O, Espaillat L, et al. De novo stress urinary incontinence after pelvic organ prolapse surgery in women without occult incontinence. Int Urogynecol J 2017; 28: 583-590.

29. Persu C, Chapple CR, Cauni V, et al. Pelvic Organ Prolapse Quantification System (POP-Q) - a new era in pelvic prolapse staging. J Med Life 2011; 4: $75-81$.

30. Von Pechmann WS, Mutone M, Fyffe J, et al. Total colpocleisis with high levator plication for the treatment of advanced pelvic organ prolapse. Am J Obstet Gynecol 2003; 189: 121-126.

31. Song X, Zhu L, Ding J, et al. Long-term follow-up after Le Fort colpocleisis: patient satisfaction, regret rate, and pelvic symptoms. Menopause 2016; 23: 621-625. 